\title{
Detection of Toxoplasma gondii DNA in horse meat from supermarkets in France and performance evaluation of two serological tests
}

\author{
Abdelkrim Aroussi ${ }^{1}$, Philippe Vignoles ${ }^{1}$, François Dalmay ${ }^{2}$, Laurence Wimel ${ }^{3}$, Marie-Laure Dardé ${ }^{1,4}$, \\ Aurélien Mercier ${ }^{1}$, and Daniel Ajzenberg ${ }^{1,4, *}$ \\ 1 INSERM, Univ. Limoges, CHU Limoges, UMR-S 1094, Laboratoire de Parasitologie, 87000 Limoges, France \\ 2 INSERM, Univ. Limoges, CHU Limoges, UMR-S 1094, Institut d'Epidémiologie Neurologique et de Neurologie Tropicale, \\ 87000 Limoges, France \\ 3 Institut Français du Cheval et de l'Équitation, Station Expérimentale, Domaine de la Valade, 19370 Chamberet, France \\ 4 Toxoplasma Biological Resource Center, CHU Limoges, 87042 Limoges, France
}

Received 21 February 2015, Accepted 14 March 2015, Published online 25 March 2015

\begin{abstract}
In France, some cases of severe toxoplasmosis have been linked to the consumption of horse meat that had been imported from the American continent where atypical strains of Toxoplasma gondii are more common than in Europe. Many seroprevalence studies are presented in the literature but risk assessment of $T$. gondii infection after horse meat consumption is not possible in the absence of validated serological tests and the unknown correlation between detection of antibodies against $T$. gondii and presence of tissue cysts. We performed magnetic-capture polymerase chain reaction (MC-PCR) to detect $T$. gondii DNA in 231 horse meat samples purchased in supermarkets in France and evaluated the performance and level of agreement of the modified agglutination test (MAT) and enzyme-linked immunosorbent assay (ELISA) in the meat juices. The serological tests lacked sensitivity, specificity, and agreement between them, and there was no correlation with the presence of $T$. gondii DNA in horse meat, raising concerns about the reliability of $T$. gondii seroprevalence data in horses from the literature. T. gondii DNA was detected in $43 \%$ of horse meat samples but the absence of strain isolation in mice following inoculation of more than 100 horse meat samples suggests a low distribution of cysts in skeletal muscles and a low risk of $T$. gondii infection associated with horse meat consumption. However, to avoid any risk of toxoplasmosis, thorough cooking of horse meat is recommended.
\end{abstract}

Key words: Toxoplasma gondii, Horse meat, Enzyme-linked immunosorbent assay, Modified agglutination test, Magnetic-capture polymerase chain reaction.

Résumé - Détection de l'ADN de Toxoplasma gondii dans la viande de cheval vendue dans les supermarchés en France et évaluation des performances de deux tests sérologiques. En France, quelques cas de toxoplasmose sévère ont été liés à la consommation de viande de cheval qui avait été importée du continent américain où les souches atypiques de Toxoplasma gondii sont plus fréquentes qu'en Europe. De nombreuses études de séroprévalence existent dans la littérature mais l'estimation du risque d'infection par $T$. gondii après consommation de viande de cheval est impossible à cause de l'absence de validation des tests sérologiques et la corrélation inconnue entre la détection des anticorps anti $T$. gondii et la présence de kystes dans les tissus. Nous avons utilisé la technique de capture magnétiqueréaction de polymérisation en chaine (MC-PCR) pour détecter l'ADN de T. gondii dans 231 échantillons de viande de cheval achetés dans des supermarchés en France et évalué la performance et le niveau d'agrément du test d'agglutination modifié (MAT) et de la méthode immuno-enzymatique ELISA dans les jus de viande. Les tests sérologiques manquaient de sensibilité, de spécificité, d'agrément entre eux et il n'y avait pas de corrélation avec la présence d'ADN de $T$. gondii dans la viande de cheval, ce qui suscite des doutes sur la fiabilité des données de séroprévalence de $T$. gondii chez les chevaux dans la littérature. L'ADN de $T$. gondii a été détecté dans $43 \%$ des échantillons de viande de cheval mais l'absence d'isolement de souche chez la souris suggère une faible répartition des kystes dans les muscles squelettiques et un faible risque d'infection par T. gondii avec la consommation de viande de cheval. Cependant, pour éviter tout risque de toxoplasmose, il est recommandé de bien cuire la viande.

\footnotetext{
*Corresponding author: ajz@unilim.fr
} 


\section{Introduction}

The intracellular protozoan $T$. gondii is able to infect all warm-blooded animals worldwide, including humans. It is estimated that one third of the world's population is chronically infected by this highly successful parasite. Humans can be infected by tachyzoites vertically during pregnancy but are more often infected later in life by bradyzoites after ingestion of tissue cysts in raw or undercooked meat, or by sporozoites after consumption of vegetables or water contaminated by oocysts in cat feces. Between 30 and $63 \%$ of $T$. gondii infections are attributed to consumption of tissue cysts in infected raw or undercooked meat [8]. Tissue cysts are the terminal life-cycle stage in the intermediate host; they are immediately infectious, and are able to remain quiescent for a very long period of time [39].

In France, after episodes of trichinellosis outbreaks and Salmonella poisoning due to horse meat consumption, the government implemented measures to protect consumers, such as prohibiting horse meat in schools (Interministerial circular of March 6, 1968). T. gondii has been isolated from meat cuts of many naturally infected animal species but tissue cysts are less frequently present in infected horses [2]. In France, some cases of severe toxoplasmosis infection due to consumption of imported horse meat have been described and genetic analyses of $T$. gondii strains revealed atypical genotypes that are highly uncommon in Europe [19, 34, 37]. Accurate evaluation of the risk of $T$. gondii infection after horse meat consumption should rely on reliable serological data for $T$. gondii infection in horses. Since the major review by Tassi in 2007 [38], additional seroprevalence data for $T$. gondii in horses has become available in the literature [3-6, 9, 20, 22, 24-28, 30, 31, 40]. One remarkable finding about $T$. gondii seroprevalence in horses in this abundant literature is its high variability between countries, from 1 to $90 \%$. This prevalence may also vary widely within the same country: $13-67 \%$ in Argentina, $14-53 \%$ in Belgium, 5-90\% in Brazil, 17-80\% in Italy, and $4-55 \%$ in Switzerland [30]. This variability in seroprevalence may have biological and epidemiological explanations, such as differences in the age of horses, their environmental lifestyle, the abundance of oocysts in the soil, and hygiene standards on farms [39]. However, an alternative explanation for the variability of $T$. gondii seroprevalence in horses may simply come from the absence of a gold standard for detecting $T$. gondii antibodies in horses and the lack of validation of the serological methods used in all these studies. The absence of a gold standard is evidenced by the diversity of serological tests used in the literature, such as enzyme-linked immunosorbent assay (ELISA), direct agglutination test (DAT), indirect immunofluorescence antibody test (IFAT), indirect hemagglutination test (IHAT), latex agglutination test (LAT), modified agglutination test (MAT), and Sabin-Feldman dye test (SFDT). The lack of validation is shown in the literature by the use of different cut-offs for a single test, without any data on sensitivity, specificity, and agreement between tests.

Our main objective was to detect $T$. gondii DNA by magnetic-capture polymerase chain reaction (MC-PCR) in horse meat destined for human consumption and to evaluate the performance of MAT and ELISA serological tests in meat juices of these samples.

\section{Materials and methods}

\subsection{Samples}

A total of 231 horse meat steak samples were purchased from supermarkets in several cities in France from November 2012 to April 2014. At least $150 \mathrm{~g}$ per meat sample was required to perform all tests (50 $\mathrm{g}$ for mouse bioassay and $100 \mathrm{~g}$ for MC-PCR). Data including lot number, geographic origin, packaging, and expiration date were collected for all horse meat samples, but the date of horse slaughter and geographic origin were not always available in the retail meat packaged for sale in the supermarkets. Horse meat samples were analyzed as quickly as possible to maximize the viability of $T$. gondii that might be present in muscles. Meat juices were directly recovered or obtained after a freezing/thawing step, allowing the muscles to release juice, then stored at $-20{ }^{\circ} \mathrm{C}$ until tested by MAT and ELISA.

A positive serum sample (THI1813) from a pony experimentally infected with $T$. gondii oocysts in 1985 was kindly provided by Dr. Dubey [11]. The MAT titer of this sample was positive up to dilution $1: 102,400$ [15].

\subsection{Magnetic-capture polymerase chain reaction (MC-PCR) of T. gondii DNA}

The MC-PCR test involved preparation of crude DNA extract from $100 \mathrm{~g}$ samples of horse meat, magnetic capture of $T$. gondii DNA, and quantitative real-time PCR targeting the $T$. gondii $529 \mathrm{bp}$ repeat element as previously described [32].

\subsection{Mouse bioassay}

A mouse bioassay was also attempted for horse meat samples with a positive MC-PCR test result and in some samples negative with this test. Two horse meat samples with a positive MC-PCR result were not inoculated because of an excessive delay between MC-PCR and bioassay. Swiss mice weighing 20-25 g were used in the bioassay. Fifty grams of horse meat samples was digested as previously described [14] and $0.5 \mathrm{~mL}$ of each digested homogenate was intraperitoneally inoculated into three mice per sample. Mice blood samples were collected 3-4 weeks later and the sera were tested for specific $T$. gondii antibodies by MAT. All procedures in mice were carried out in compliance with ethical rules and approved by the Regional Ethics Committee Limousin (Registration Number: CREEAL 3-07-2012).

\subsection{Modified agglutination test (MAT)}

Both T. gondii RH strain antigen preparation and MAT test were performed as previously described [10]. The test was 
considered positive when a layer of agglutinated parasites formed in wells. Meat juices were tested at five serial dilutions $(1: 10,1: 20,1: 40,1: 100$, and 1:400). The cut-offs for MAT were designated as MAT $>0$, MAT $>1: 10$, MAT $>1: 20$, and MAT $>1: 40$. At the MAT $>0$ cut-off, the positive samples were those with a test positive at dilutions 1:10, 1:20, $1: 40,1: 100$, and 1:400. At the MAT $>1: 10$ cut-off, the positive samples were those with a test positive at dilutions 1:20, $1: 40,1: 100$, and 1:400. At the MAT > 1:20 cut-off, the positive samples were those with a test positive at dilutions 1:40, 1:100, and 1:400. And lastly, at the MAT > 1:40 cut-off, the positive samples were those with a test positive at dilutions $1: 100$ and $1: 400$.

\subsection{Enzyme-linked immunosorbent assay (ELISA)}

Horse IgG antibodies to $T$. gondii were tested by using the commercial kit multi-species ID Screen ${ }^{\circledR}$ Toxoplasmosis Indirect (IDVet, Montpellier, France). The test procedure was performed according to the manual provided by the manufacturer. The optical density (OD) values were read at $450 \mathrm{~nm}$ using a microplate spectrophotometer Thermo Scientific $^{\mathrm{TM}}$ Multiskan ${ }^{\mathrm{TM}}$ GO.

\subsection{Statistical analysis}

Cut-off values for MAT and ELISA were selected by receiver operating characteristic (ROC) analysis. In horse meat juices, the cut-offs were estimated by using MC-PCR as the reference test. For the commercial ELISA test, the cut-off was also determined by testing several dilutions of the positive horse serum THI1813. Comparisons of matched pair results between two tests with the selected cut-offs were performed by the McNemar test. Kappa coefficient was used to estimate agreement between tests for the detection of $T$. gondii infection in meat juice.

\section{Results}

\subsection{Sampling data and test results}

Most of the horse meat sampled in this study was from the Americas, with three major export countries: $40 \%$ from Argentina, 20\% from Canada, and 14\% from Mexico (Table 1). Full data including the list of horse meat samples with geographic origin and test results are available in the Supplementary material.

\subsection{Mouse bioassay}

No T. gondii strain was isolated following inoculation of 118 horse meat samples in mice, including 97 with positive MC-PCR results and 21 with negative MC-PCR results (Supplementary material).

\subsection{Cut-off determination for MAT and ELISA and level of agreement between tests}

The ROC curves and calculations of sensitivity (Se) and specificity (Sp) allowed us to identify the most suitable cut-offs

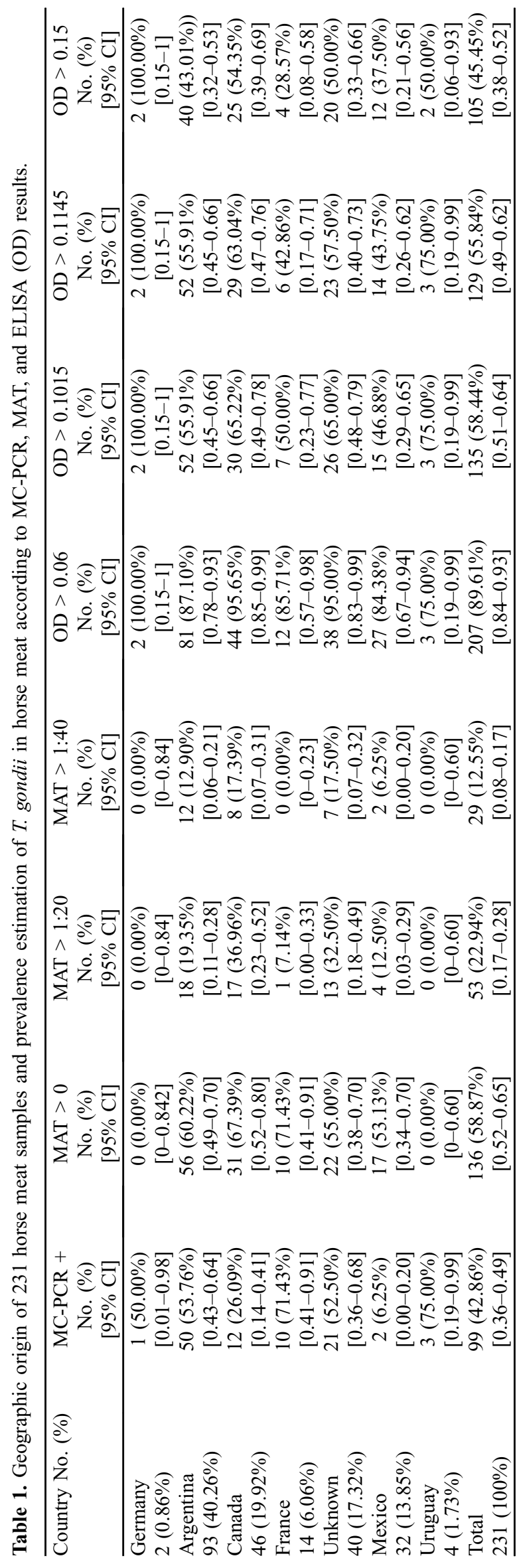




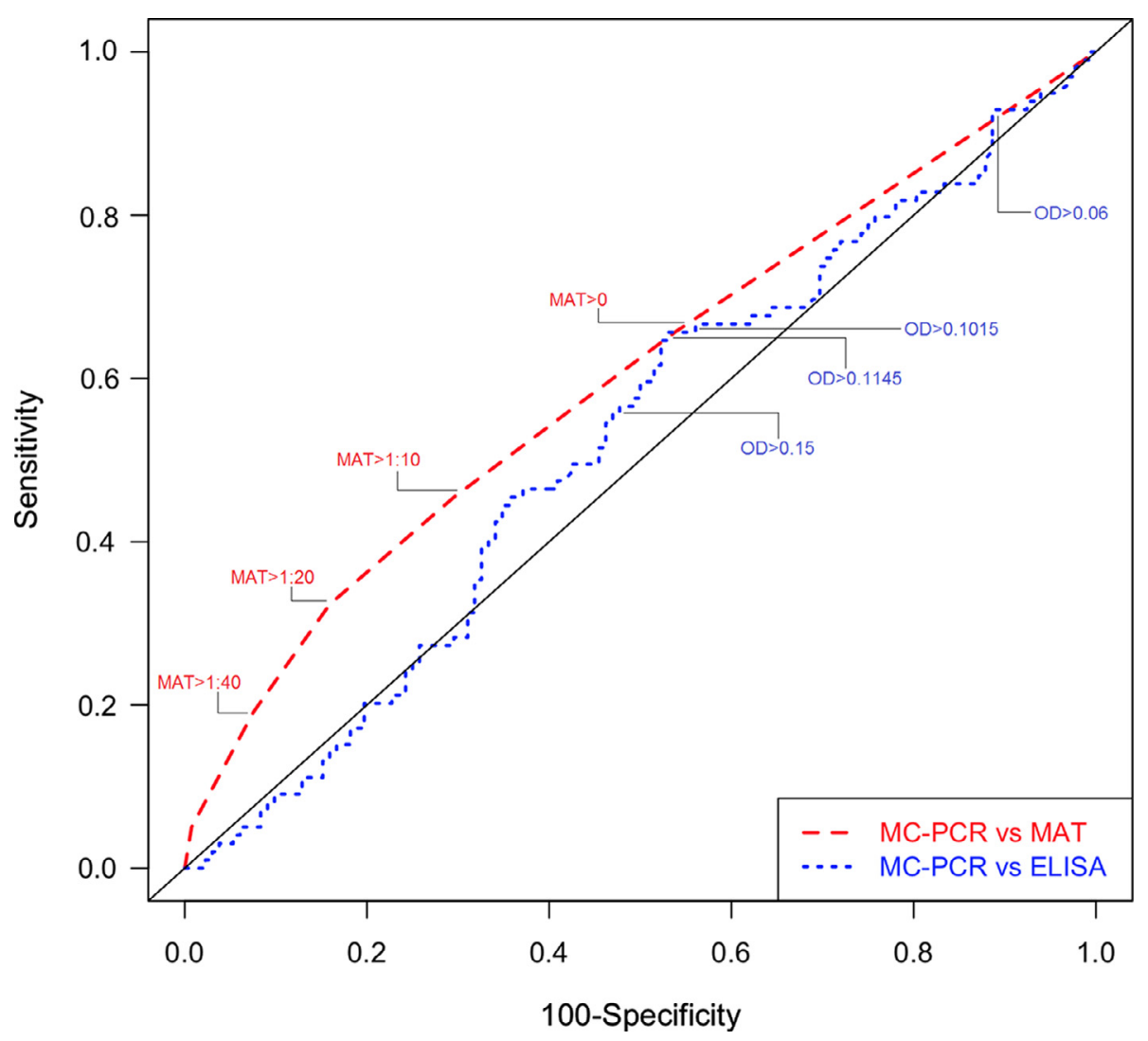

Figure 1. Receiver operating characteristics (ROC) analysis of ELISA and MAT vs. MC-PCR in meat juice samples.

that represented the best balance between sensitivity and specificity for the two serological tests MAT and ELISA in horse meat samples (Fig. 1). The best balance between sensitivity and specificity was observed at cut-offs MAT $>0$ (sensitivity of $66 \%$ and specificity of $46 \%$ ), OD $>0.1015$ (sensitivity of $66 \%$ and specificity of $47 \%$ ), and OD $>0.1145$ (sensitivity of $62 \%$ and specificity of $48 \%$ ) for ELISA in horse meat samples (Fig. 1 and Table 2). The area under the ROC curve ranged from 0.52 for ELISA to 0.60 for MAT, representing an acceptable level of precision. Other ELISA cut-offs such as $\mathrm{OD}>0.06$ and $\mathrm{OD}>0.15$ were subsequently identified by crossing ROC curve results with different MAT cut-offs at $>1: 10,>1: 20$, and $>1: 40$, and were also included in our additional calculations. The serial dilutions of the positive horse serum THI1813 showed that the identified cut-off values of ELISA (OD $>0.06, \quad \mathrm{OD}>0.1015, \quad \mathrm{OD}>0.1145$, and $\mathrm{OD}>0.15)$ were consistent with the negativity limits of the positive control (data not shown).

The kappa values used to estimate the agreement between MC-PCR vs. ELISA and MC-PCR vs. MAT for the identified cut-offs were low with a range between 0.02 and 0.12 for the ELISA and between 0.11 and 0.17 for the MAT (Table 2). These results indicate a poor agreement between MC-PCR vs. ELISA and MC-PCR vs. MAT. The McNemar test was significant for the cut-offs $\mathrm{OD}>0.06$, OD $>0.1015$, $\mathrm{OD}>0.1145$, and MAT $>0$ (Table 2). At these cut-off values, the discordances were significantly more frequent in samples with negative results with MC-PCR and positive results with
ELISA or MAT than in samples with positive results with MC-PCR and negative results with ELISA or MAT. At cutoff values $\mathrm{OD}>0.15$ and MAT $>1: 10$, the McNemar test was not significant (Table 2), which means that the paired discordances (samples negative with MC-PCR and positive with ELISA or MAT vs. samples positive with MC-PCR and negative with ELISA or MAT) occurred randomly. At the MAT $>1: 20$ and MAT $>1: 40$ cut-off values, the McNemar test was significant (Table 2), and the discordances were significantly more frequent in samples with positive results with MC-PCR and negative results with MAT than in samples with negative results with MC-PCR and positive results with MAT. This result showed that the MAT $>1: 20$ and MAT $>1: 40$ cut-offs have poor sensitivity for detecting horse meat samples infected with $T$. gondii.

\subsection{Prevalence data}

According to MC-PCR results, T. gondii DNA was found in $99(43 \%)$ of 231 horse meat samples (Table 1). By using the serological MAT and ELISA tests, the T. gondii prevalence varied from 13 to $90 \%$ depending on the cut-off used (Table 1). The three cut-offs for MAT and ELISA that were determined by our statistical analysis as having the best balance between sensitivity and specificity showed a similar prevalence with both techniques: $59 \%$ (MAT $>0$ ), 58\% (OD > 0.1015), and $56 \%(\mathrm{OD}>0.1145)$. 


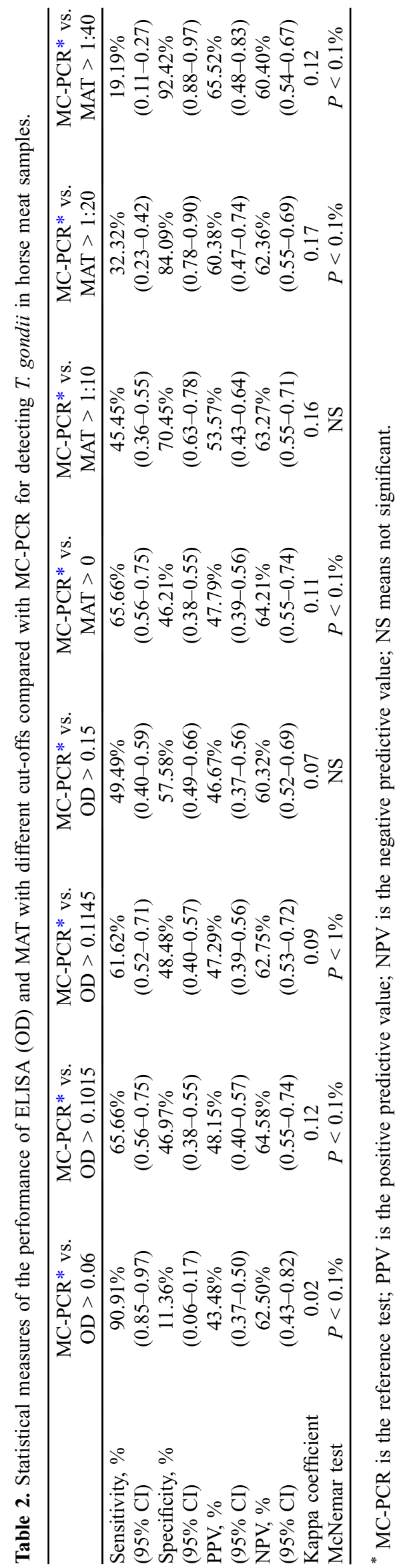

\section{Discussion}

Our primary goal was to assess the risk of $T$. gondii infection after consumption of horse meat based on recent reports in France of several cases of severe toxoplasmosis after consumption of horse meat imported from South and North America [34]. Seroprevalence data can give an indication of the risk of human toxoplasmosis by eating meat from one animal species only if the detection of specific antibodies and the presence of tissue cysts have a strong correlation in this animal species [33]. This correlation is excellent in some animal species such as pigs and sheep [17, 23], poor in other animal species such as cattle [33], and totally unknown in the vast majority of animal species. In numerous animal species, especially wild ones, there is no gold standard for estimating T. gondii seroprevalence and the performances of the usual serological tests used for detecting $T$. gondii antibodies, such as ELISA, DAT, IFAT, IHAT, LAT, MAT, and SFDT, have never been evaluated. However, it is common practice to assess $T$. gondii seroprevalence by using one test with an arbitrary cutoff and without any data on the sensitivity, specificity, and agreement with other tests. Taking bats as an example, a study in China reported $T$. gondii seroprevalence data in different species of bats by using the MAT with a cut-off at 1:25, without any explanation on why they used this test at this cut-off, probably because they read that it was validated in pigs [13]. However, bats are not pigs and what is true for one animal species is not true for another. A Brazilian study tested the agreement with Cohen's kappa coefficient between MAT and IFAT in bat sera [7]. The authors showed that the agreement was poor and could not evaluate the specificity and sensitivity of both tests for the diagnosis of toxoplasmosis in bat species. With all these limitations, one can wonder how far we are from the real seroprevalence of $T$. gondii in bats in the Chinese study.

T. gondii seroprevalence studies are much more abundant in horses than in bats in the literature [38], but they face the same problem: there is no gold standard - nothing is known about test performances and agreement between tests. This issue was raised by Dubey many years ago when he observed no correlation between the DT and the MAT for detecting T. gondii in horses slaughtered for food in North America [18]. The conclusion of this study was that an accurate assessment of prevalence was not possible until additional studies are carried out to determine the sensitivity and specificity of the various serological tests for toxoplasmosis in horses. We evaluated the performances of MAT and ELISA serological tests in meat juice from 231 horse meat samples by comparing them with the detection of $T$. gondii DNA by MC-PCR in these samples. For the evaluation of the serological tests in horse meat samples, MC-PCR was considered as the reference test in this study because the detection of $T$. gondii DNA in horse meat samples always reveals, in the absence of cross contamination, the presence of $T$. gondii. MC-PCR is a newly developed technique with a much higher sensitivity than isolation of total DNA from a fraction of the crude extract [32]. However, the absence of detection of $T$. gondii DNA does not necessarily mean that the horse was not infected by $T$. gondii, because the distribution of tissue cysts may be low and inhomogeneous 
in muscle samples [33]. Though sensitivity of MC-PCR is a matter of concern as a reference test in this study with the relatively small sample used (150 g), it can be considered acceptable with a detection limit estimated at 230 parasites per $100 \mathrm{~g}$ of meat, making it possible to detect one cyst of $T$. gondii in $100 \mathrm{~g}$ of meat [32].

The conventional gold standard for detecting $T$. gondii cysts in tissues is bioassay in mice or cats [23]. We used bioassay in mice in our study not as a reference test but in order to isolate $T$. gondii strains from horse meat for further genotyping. Because mouse bioassay is time-consuming, we inoculated the horse meat samples that were positive with the MC-PCR assay as a priority. All the bioassays were negative; it was not possible to isolate a single strain following mouse bioassay of 118 horse meat samples. This demonstrates that bioassays in mice are far less sensitive than MC-PCR for detecting T. gondii in horse meat samples and validates our choice of MC-PCR as the reference test. A concern about $T$. gondii viability due to excessive delay between the slaughter of the horses and the bioassay of meat samples may be addressed to explain this absence of strain isolation in mice, even though tissue cysts are relatively resistant to changes in temperature and remain infectious in refrigerated $\left(1\right.$ to $\left.4{ }^{\circ} \mathrm{C}\right)$ carcasses or minced meat for up to 3 weeks [12]. Testing muscles from fresh carcasses collected in abattoirs would probably greatly enhance the sensitivity of bioassay. Another explanation can be found in the $\mathrm{Ct}$ (threshold cycle) values of MC-PCR that were very high for the horse meat samples (median $=38.59$ ), indicating a very low DNA concentration which is known to be associated with poor sensitivity in mouse bioassays [21]. Direct genotyping in horse meat samples with microsatellite markers was not attempted because of the insufficient amount of $T$. gondii DNA to allow PCR-based amplification of single-copy markers $[1,32]$. Like in cattle, it appears to be very difficult to isolate strains from horse meat probably because the distribution of cysts is very low in skeletal muscles $[2,16]$. Other horse tissues such as brain, heart, or diaphragm collected in abattoirs may have a higher $T$. gondii cyst load than in skeletal muscles and may enhance the sensitivity of bioassay as shown in one study in Egypt [36].

Based on kappa values, our results indicate poor agreement between MC-PCR and ELISA or MAT at different cut-offs identified by ROC curves analysis in horse meat samples. The prevalence of $T$. gondii in 231 horse meat samples was $43 \%$ with MC-PCR in our study. By using the serological tests MAT and ELISA, the T. gondii prevalence varied considerably, from 13 to $90 \%$, depending on the cut-off used. Our analysis identified three cut-offs for MAT and ELISA as having the best balance between sensitivity and specificity: OD $>0.1015$ and $\mathrm{OD}>0.1145$ for ELISA and MAT $>0$. However, at these cut-offs, the sensitivity reached a maximum of $66 \%$ and the specificity a maximum of $48 \%$ which is very low in comparison with values for other animal species such as pigs or sheep in which sensitivity and specificity values are above $85 \%$ for both MAT and ELISA [23, 29, 35]. With such low performance of MAT and ELISA in horses, we do not recommend use of serological tests or serological data from the literature to assess the risk of toxoplasmosis after consumption of horse meat. Based on the fact that no viable strain was isolated after mouse bioassay, our study suggests that this risk is low but should not be neglected in France because horse meat is imported from Latin American countries where atypical and pathogenic strains are more common than in Europe, and because eating raw or undercooked meat is common in France. The health authorities should undertake a large-scale survey on a representative sample of imported horses slaughtered for food to assess the risk of toxoplasmosis for consumers. Rather than using retail meat packaged for sale from supermarkets, the detection of $T$. gondii by bioassay should be done on fresh carcasses to maximize the viability of the parasite. To avoid any risk of severe toxoplasmosis, the consumer must cook the horse meat by reaching an internal temperature above $70{ }^{\circ} \mathrm{C}$ in all parts of the meat, which will kill the cysts of $T$. gondii if present.

Acknowledgements. The authors are greatly indebted to Dr. J.P. Dubey who provided the positive $T$. gondii horse serum, Dr. J.W.B. van der Giessen and Dr. M. Opsteegh (RIVM Instituut, Utrecht, Netherlands) who hosted the first author of this study in their laboratories to learn the MC-PCR technique. We are also grateful for the helpful contributions of M. Gatet, R. Mouzet, and H. Riahi who participated in horse meat sampling and technical support.

\section{Conflict of interest}

The authors have no relevant affiliations or financial involvement with any organization or entity with a financial interest in or financial conflict with the subject matter or materials discussed in the manuscript. This includes employment, consultancies, honoraria, stock ownership or options, expert testimony, grants or patents received or pending, or royalties.

\section{References}

1. Ajzenberg D, Collinet F, Mercier A, Vignoles P, Dardé ML. 2010. Genotyping of Toxoplasma gondii isolates with 15 microsatellite markers in a single multiplex PCR assay. Journal of Clinical Microbiology, 48(12), 4641-4645.

2. Al-Khalidi NW, Dubey JP. 1979. Prevalence of Toxoplasma gondii infection in horses. Journal of Parasitology, 65(2), 331-334.

3. Alanazi AD, Alyousif MS. 2011. Prevalence of antibodies to Toxoplasma gondii in horses in Riyadh Province, Saudi Arabia. Journal of Parasitology, 97(5), 943-945.

4. Alvarado-Esquivel C, Rodriguez-Pena S, Villena I, Dubey JP. 2012. Seroprevalence of Toxoplasma gondii infection in domestic horses in Durango State, Mexico. Journal of Parasitology, 98(5), 944-945.

5. Bartova E, Sedlak K, Syrova M, Literak I. 2010. Neospora spp. and Toxoplasma gondii antibodies in horses in the Czech Republic. Parasitology Research, 107(4), 783-785.

6. Boughattas S, Bergaoui R, Essid R, Aoun K, Bouratbine A. 2011. Seroprevalence of Toxoplasma gondii infection among horses in Tunisia. Parasite and Vectors, 4, 218.

7. Cabral AD, D'Auria SR, Camargo MC, Rosa AR, Sodre MM, Galvao-Dias MA, Jordao LR, Dubey JP, Gennari SM, Pena HF. 2014. Seroepidemiology of Toxoplasma gondii infection in bats from Sao Paulo city, Brazil. Veterinary Parasitology, 206(3-4), 293-296. 
8. Cook AJ, Gilbert RE, Buffolano W, Zufferey J, Petersen E, Jenum PA, Foulon W, Semprini AE, Dunn DT. 2000. Sources of Toxoplasma infection in pregnant women: European multicentre case-control study. European Research Network on Congenital Toxoplasmosis. British Medical Journal, 321(7254), 142-147.

9. Dangoudoubiyam S, Oliveira JB, Viquez C, Gomez-Garcia A, Gonzalez O, Romero JJ, Kwok OC, Dubey JP, Howe DK. 2011. Detection of antibodies against Sarcocystis neurona, Neospora spp., and Toxoplasma gondii in horses from Costa Rica. Journal of Parasitology, 97(3), 522-524.

10. Desmonts G, Remington JS. 1980. Direct agglutination test for diagnosis of Toxoplasma infection: method for increasing sensitivity and specificity. Journal of Clinical Microbiology, 11(6), 562-568.

11. Dubey JP. 1985. Persistence of encysted Toxoplasma gondii in tissues of equids fed oocysts. American Journal of Veterinary Research, 46(8), 1753-1754.

12. Dubey JP. 1988. Long-term persistence of Toxoplasma gondii in tissues of pigs inoculated with Toxoplasma gondii oocysts and effect of freezing on viability of tissue cysts in pork. American Journal of Veterinary Research, 49(6), 910-913.

13. Dubey JP. 1997. Validation of the specificity of the modified agglutination test for toxoplasmosis in pigs. Veterinary Parasitology, 71(4), 307-310.

14. Dubey JP. 1998. Refinement of pepsin digestion method for isolation of Toxoplasma gondii from infected tissues. Veterinary Parasitology, 74(1), 75-77.

15. Dubey JP, Desmonts G. 1987. Serological responses of equids fed Toxoplasma gondii oocysts. Equine Veterinary Journal, 19(4), 337-339.

16. Dubey JP, Jones JL. 2008. Toxoplasma gondii infection in humans and animals in the United States. International Journal for Parasitology, 38(11), 1257-1278.

17. Dubey JP, Sundar N, Hill D, Velmurugan GV, Bandini LA, Kwok OC, Majumdar D, Su C. 2008. High prevalence and abundant atypical genotypes of Toxoplasma gondii isolated from lambs destined for human consumption in the USA. International Journal for Parasitology, 38(8-9), 999-1006.

18. Dubey JP, Thulliez P, Romand S, Kwok OC, Shen SK, Gamble HR. 1999. Serologic prevalence of Toxoplasma gondii in horses slaughtered for food in North America. Veterinary Parasitology, 86(4), 235-238.

19. Elbez-Rubinstein A, Ajzenberg D, Dardé ML, Cohen R, Dumètre A, Yera H, Gondon E, Janaud JC, Thulliez P. 2009. Congenital toxoplasmosis and reinfection during pregnancy: case report, strain characterization, experimental model of reinfection, and review. Journal of Infectious Diseases, 199(2), 280-285.

20. Evers F, Garcia JL, Navarro IT, Zulpo DL, Nino Bde S, Ewald MP, Pagliari S, Almeida JC, Freire RL. 2013. Diagnosis and isolation of Toxoplasma gondii in horses from Brazilian slaughterhouses. Revista Brasileira de Parasitologia Veterinária, 22(1), 58-63.

21. Filisetti D, Cocquerelle V, Pfaff A, Villard O, Candolfi E. 2010. Placental testing for Toxoplasma gondii is not useful to diagnose congenital toxoplasmosis. Pediatric Infectious Disease Journal, 29(7), 665-667.

22. Finger MA, Villalobos EM, Lara Mdo C, Cunha EM, Barros Filho IR, Deconto I, Dornbusch PT, Ullmann LS, Biondo AW. 2013. Detection of anti-Toxoplasma gondii antibodies in carthorses in the metropolitan region of Curitiba, Parana. Revista Brasileira de Parasitologia Veterinária, 22(1), 179-181.
23. Gamble HR, Dubey JP, Lambillotte DN. 2005. Comparison of a commercial ELISA with the modified agglutination test for detection of Toxoplasma infection in the domestic pig. Veterinary Parasitology, 128(3-4), 177-181.

24. Garcia-Bocanegra I, Cabezon O, Arenas-Montes A, Carbonero A, Dubey JP, Perea A, Almeria S. 2012. Seroprevalence of Toxoplasma gondii in equids from Southern Spain. Parasitology International, 61(3), 421-424.

25. Ghazy AA, Shaapan RM, Abdel-Rahman EH. 2007. Comparative serological diagnosis of toxoplasmosis in horses using locally isolated Toxoplasma gondii. Veterinary Parasitology, 145(1-2), 31-36.

26. Jakubek EB, Lunden A, Uggla A. 2006. Seroprevalences of Toxoplasma gondii and Neospora sp. infections in Swedish horses. Veterinary Parasitology, 138(3-4), 194-199.

27. Kouam MK, Diakou A, Kanzoura V, Papadopoulos E, Gajadhar AA, Theodoropoulos G. 2010. A seroepidemiological study of exposure to Toxoplasma, Leishmania, Echinococcus and Trichinella in equids in Greece and analysis of risk factors. Veterinary Parasitology, 170(1-2), 170-175.

28. Lopes AP, Sousa S, Dubey JP, Ribeiro AJ, Silvestre R, Cotovio M, Schallig HD, Cardoso L, Cordeiro-da-Silva A. 2013. Prevalence of antibodies to Leishmania infantum and Toxoplasma gondii in horses from the north of Portugal. Parasite and Vectors, 6,178 .

29. Mainar-Jaime RC, Barberan M. 2007. Evaluation of the diagnostic accuracy of the modified agglutination test (MAT) and an indirect ELISA for the detection of serum antibodies against Toxoplasma gondii in sheep through Bayesian approaches. Veterinary Parasitology, 148(2), 122-129.

30. Matsuo K, Kamai R, Uetsu H, Goto H, Takashima Y, Nagamune K. 2014. Seroprevalence of Toxoplasma gondii infection in cattle, horses, pigs and chickens in Japan. Parasitology International, 63(4), 638-639.

31. Miao Q, Wang X, She LN, Fan YT, Yuan FZ, Yang JF, Zhu XQ, Zou FC. 2013. Seroprevalence of Toxoplasma gondii in horses and donkeys in Yunnan Province, Southwestern China. Parasite and Vectors, 6, 168.

32. Opsteegh M, Langelaar M, Sprong H, den Hartog L, De Craeye S, Bokken G, Ajzenberg D, Kijlstra A, van der Giessen J. 2010. Direct detection and genotyping of Toxoplasma gondii in meat samples using magnetic capture and PCR. International Journal of Food Microbiology, 139(3), 193-201.

33. Opsteegh M, Teunis P, Zuchner L, Koets A, Langelaar M, van der Giessen J. 2011. Low predictive value of seroprevalence of Toxoplasma gondii in cattle for detection of parasite DNA. International Journal for Parasitology, 41(3-4), 343-354.

34. Pomares C, Ajzenberg D, Bornard L, Bernardin G, Hasseine L, Dardé ML, Marty P. 2011. Toxoplasmosis and horse meat, France. Emerging Infectious Diseases, 17(7), 1327-1328.

35. Shaapan RM, El-Nawawi FA, Tawfik MA. 2008. Sensitivity and specificity of various serological tests for the detection of Toxoplasma gondii infection in naturally infected sheep. Veterinary Parasitology, 153(3-4), 359-362.

36. Shaapan RM, Ghazy AA. 2007. Isolation of Toxoplasma gondii from horse meat in Egypt. Pakistan Journal of Biological Sciences, 10(1), 174-177.

37. Sobanski V, Ajzenberg D, Delhaes L, Bautin N, Just N. 2013. Severe toxoplasmosis in immunocompetent hosts: be aware of atypical strains. American Journal of Respiratory and Critical Care Medicine, 187(10), 1143-1145. 
38. Tassi P. 2007. Toxoplasma gondii infection in horses. A review. Parassitologia, 49(1-2), 7-15.

39. Tenter AM. 2009. Toxoplasma gondii in animals used for human consumption. Memórias do Instituto Oswaldo Cruz, 104(2), 364-369.
40. Yang N, Mu MY, Yuan GM, Zhang GX, Li HK, He JB. 2013. Seroprevalence of Toxoplasma gondii in slaughtered horses and donkeys in Liaoning Province, Northeastern China. Parasite and Vectors, 6, 140.

Cite this article as: Aroussi A, Vignoles P, Dalmay F, Wimel L, Dardé M-L, Mercier A \& Ajzenberg D: Detection of Toxoplasma gondii DNA in horse meat from supermarkets in France and performance evaluation of two serological tests. Parasite, $2015,22,14$.

\section{- PARASTE}

An international open-access, peer-reviewed, online journal publishing high quality papers on all aspects of human and animal parasitology

Reviews, articles and short notes may be submitted. Fields include, but are not limited to: general, medical and veterinary parasitology; morphology, including ultrastructure; parasite systematics, including entomology, acarology, helminthology and protistology, and molecular analyses; molecular biology and biochemistry; immunology of parasitic diseases; host-parasite relationships; ecology and life history of parasites; epidemiology; therapeutics; new diagnostic tools.

All papers in Parasite are published in English. Manuscripts should have a broad interest and must not have been published or submitted elsewhere. No limit is imposed on the length of manuscripts.

Parasite (open-access) continues Parasite (print and online editions, 1994-2012) and Annales de Parasitologie Humaine et Comparée (1923-1993) and is the official journal of the Société Française de Parasitologie. 